\title{
RAIZ DO RACISMO: DESIGUALDADE DE DIREITO
}

\author{
Palmira Aparecida de Andrade Souza \\ Mestranda em História pela Universidade Estadual de Goiás - UEG. \\ E-mail: palmiraandradsouza@gmail.com \\ Antônio Carlos Freire Sampaio \\ LAGEPOP/IG/Universidade Federal de Uberlândia - UFU.
}

\begin{abstract}
RESUMO
O presente estudo propõe uma reflexão sobre a Raiz do Racismo no Brasil pelo viés da desigualdade de direito entre negro e branco. Trazem alguns elementos e passagem histórica vivenciada pelos afros no período Colonial, Império, República. Como sabemos não foi uma relação de justiça, igualdade de direito, respeito à pessoa humana. Dentro de um processo de produção econômica, que envolveu várias etnias tais como, o branco, negro, índio, asiático. É possível observar, por meio de estudos e vivencia, que é uma memória de conflito, dor, mágoa, fata de justiça igualitária. E um Estado racista no sentido que sempre serviu e aliaram-se às classes dominantes. O racismo, no país escravocrata, é estrutural e ao longo de muitos anos gerações vêm convivendo com a violência ideológica, física, psicologia praticada não só com a raça negra, mas com índios, mestiços, ciganos entre outros. Para os subjugados são lembranças que se relacionam com o passado e o presente, não resolvidas. Situação melindre atualmente, por ter feito parte de uma estrutura, muitos termos, palavras utilizadas passam despercebidos para quem usa sem propriedade, conhecimento de causa, mas para a vítima impacta de maneira irreparável, fere a alma. A referência que os identifica é exclusão, cerceamento de ambas as naturezas, em vários espaços e tempos. A fonte de pesquisa é bibliográfica e em documentos oficiais como Leis, entre outros. Sustentar a argumentação teórica em escritos de Cardoso (1997) e Reis (2005) que pesquisa sobre a questão racial no país, discute a história de africanos, descendentes, crioula, libertos no processo escravocrata. A intenção é trazer uma reflexão sobre elementos na trajetória vivenciada por pessoas negras, para compreender a raiz do racismo.
\end{abstract}

Palavras chave: Racismo. Igualdade. Direito. Raça.

\section{INTRODUÇÃO}

Atualmente a prática do racismo constitui em um crime inafiançável, uma conquista dos grupos, militantes defensores da causa. Racismo é o ato de discriminar raças diferentes, agredir psicologicamente, negar o direito a igualdade social. Embora as leis no Brasil normalmente não saíssem do papel, cabe evidenciar que existem, mas, quase sempre apenas na teoria, longe de ser aplicada ou ser regra sem distinção no cotidiano do brasileiro.

Como é notório, no decorrer de trezentos anos em que, especialmente o africano foi trazido para o continente americano, se tornou na época geograficamente conhecida como o "Novo Mundo". Foram milhares trazidos contra sua vontade não respeitando sua cultura. Atitude muito justificada pela crença na ideia de superioridade étnica. Para 
melhor compreender a condição de vida que o africano capturado na África passou a enfrentar aqui, o Artigo $1^{\circ}$ do Estatuto da Igualdade Racial dispõe:

Discriminação racial ou étnico-racial: toda distinção, exclusão, restrição ou preferência baseada em raça, cor, descendência ou origem nacional ou étnica que tenha por objeto anular ou restringir o reconhecimento, gozo ou exercício, em igualdade de condições, de direitos humanos e liberdades fundamentais nos campos político, econômico, social, cultural ou em qualquer outro campo da vida pública ou privada. (BRASIL, 2010).

A teoria, conforme o artigo $1^{\circ}$ do Estatuto da Igualdade Racial apresenta igualdade de direito entre outros quesitos necessários ao bem-estar social, psicológico. É plausível, embora a efetivação depende de processos judiciais que demoram anos e a maioria das vezes nem é concluído, além do desgaste processual.

Mas a raiz do racismo é um problema que chegou ao século XXI com tanto avanço nas ciências, meio de comunicação, tecnologia. Para melhor conhecer o fato, tido por muitos, como uma vergonha, nacional e internacional para a humanidade, é relevante refletir nas condições que os africanos viviam na pátria natal, o Continente Africano. Para se ter uma ideia da amplitude da conjuntura do problema, Reis (1986) em seus escritos diz:

Final do século XVIII, o tráfico de africanos para a Bahia se intensificou e se concentrou na região do Golfo de Benin, sudoeste da atual Nigéria foram importados milhares de escravos, vítimas de revoltas políticas, conflito étnico e guerras relacionadas com a expansão do Islã na região. (REIS, 1986. p.100).

Nada mudou em relação à dignidade humana. As condições conflitantes ao chegar ao Brasil foram intensificadas no decorrer da história de suas vivências. Faz-se oportuno para entender as raízes da violência sofrida pela etnia negra, hoje chamada de racismo, pensar na maneira como eram tratados e retirados de diversos países da África com o objetivo de cativá-los. Os escritos de Reis (1986, p. 100) possibilitam afirmar que a vida dos negros nem na África e nem no Brasil, significou respeito, qualidade de vida, por exemplo:

\footnotetext{
A partir do final do século XVIII, o trafico de africanos, para a Bahia se intensificou e se concentrou na região do golfo de Benin, Sudoeste da atual Nigéria. Foram importados milhares de escravos, vítimas de revoltas políticas, conflitos étnicos e guerras relacionadas com a expansão do Islã na região.
}

Outra questão que deve ser analisada refere-se à ideologia arquitetada pelos que detinham o poder de encarcerar os africanos não deixar em mesmos locais aqueles que 
tivessem laços familiares, falassem a mesma língua. Não havendo igualdade de cultura, língua, costumes, religiosidade dificultaria a união dos cativos e com isso, dificultaria para êxito em fugas e rebeliões. Para melhor compreender como se dá o processo hegemônico numa relação de poder, Cardoso (1997) traz a opinião de Hannah Arendt quando declara que "o poder se definiria como "a habilidade humana não só de agir, mas de agir em concerto, ou seja, o poder é um poder das pessoas umas em relação às outras, é uma ação conjunta ou grupal [...].” (CARDOSO, 1997, p.128).

Sim, a submissão dos cativos ao trabalho sem remuneração, direito de descanso, respeito as suas peculiaridades, diferenças étnicas raciais, cultural, não foi uma ação isolada, foi um produto de união de pessoas representantes de países com interesses afins, que em atitudes oportunistas e eurocêntrica evidenciava problemas sociais, políticos, econômico, étnicos, tribais e dominação colonial (século XI,XII na Ásia; América; África) no uso do poder subjugaram negros à condições de coisas, produto de compra e venda, uma mercadoria.

O eurocentrismo já tinha expressividade na expansão marítima e ocupação territorial dos europeus nos países colonizados nos séculos XVI, XVII, XVIII, não sendo uma prática de encarcerar o negro exclusiva do Brasil, outros países também lucraram com o trabalho escravo que submeteram tanto o nativo - índio - como os africanos não só a mão de obra forçada, mas a religiosidade, costumes do Velho Mundo.

No tráfico de navios negreiros, não havia qualidade. As condições conforme descrevem a historiografia tradicional positivista, eram péssimas faltava higiene, alimentação e muitos não resistiam e até suicidavam. A princípio, o destino final da viagem era as fazendas para o trabalho na produção primária de cana de açúcar, mineração e depois café.

As mulheres eram levadas para exercer trabalhos domésticos, nas sedes da fazenda, onde habitava o proprietário da terra e sua família. Com o aumento da agricultura e a formação dos centros urbanos, local de escoamento da produção de açúcar e depois outros como a produção aurífera, cafeeira, o africano também compunham o contingente urbano. Não na condição de cidadãos, despossuídos de direitos, até mesmos os alforriados, os nascidos no país, chamados de crioulos que tinha a falsa ideia que possuíam vantagens sobre os demais não usufruíam os mesmos direitos que os brancos, nem mesmo nas vestimentas (REIS, 1986). 
As roupas caracterizavam a situação financeira, não sendo permitido aos negros usarem os mesmos trajes que os brancos. Havia lei, para punir como: multas, açoites, exílio, degredo, espancamento em público aos que desobedecessem, executadas pelo Estado que era extremamente racista (RUSSELL, 2005). Obrigados a trabalharem sem remuneração, descanso, sem qualidade de vida, sem respeito a própria dignidade e em muitos casos e em situação de resistência eram brutalmente punidos, geralmente em lugares públicos para exemplificar. Um exemplo trata-se do Pelourinho em Salvador, que depois passou a ser um patrimônio histórico, lugar de visitas turísticas. A memória das humilhações que um ser humano possa ter vivido.

Lembrando que o africano constituía uma mercadoria, tanto que havia os escravos de ganho, isto é, os que trabalhavam para dar lucro aos seus proprietários. Sendo bens, não era lucro para o proprietário sacrificar o trabalhador na condição de escravo. A exploração não consistia só em trabalho, mas também sexual. Muitas cativas eram obrigadas a servir sexualmente aos seus senhores. Fato que muito contribuiu para o clareamento da população e a miscigenação. Embora, não representou aceitação e respeito pela cor e daí pesando para a não aceitação a origem da progenitora.

O processo em que foi conduzido o sistema escravagista é de conhecimento de muitas pessoas devido ao impacto emocional que o fato acontecido provocara por ser cruel, avassalador tanto para os nativos ${ }^{1}$, que também foram escravizados, submetido a sexo forçado, uma cultura religiosa, linguística que não eram as suas, quanto para os africanos, que também vivenciaram o mesmo. Negados o direito de viver em família, praticar seus rituais e crenças religiosas, no caso dos africanos.

A reflexão que incomoda é o pensamento ideológico que sustenta as relações de poder entre os iguais - os humanos, no processo de produção econômica, que deveria ser para garantir as necessidades de todos. A ideia da superioridade racial, fomentada, alimentada por aqueles que dela se beneficiara durante décadas; e as pessoas que tem "sede" de poder; provavelmente.

A sociedade brasileira passou por um longo processo de miscigenação, aculturação, difusão de raças, cores, etnias e muitas políticas excludentes e repressoras.

\footnotetext{
1 Nativas são pessoas que viviam na América antes dos europeus, sendo que após a chegada dos dominadores foram chamados de índios por terem entendido que haviam chegado as Índias na Ásia, lugar que consistia no objetivo das grandes navegações, continuar um comércio já existente. Conforme a historiografia tradicional positivista, (que dava ênfase para os documentos sem preocupar com a análise dos mesmos), por motivo de desentendimento no percurso da rota, tiveram que mudar o curso da viagem e consequentemente chegaram ao Novo Mundo, descoberto posteriormente que não era as Índias.
} 
É notório a negligência do Estado com a miséria, desigualdade social de direito entre a população principalmente com os despossuídos de bens materiais e intelectual, negros, índios, os que apresentam orientação sexual diferenciada (os heterossexuais, transexuais...), ciganos as pessoas que vivem em situação de rua, os dependentes químicos.

A História sendo uma ciência do presente que envolve o homem com suas inquietudes em uma relação de passado presente, possibilita repensar e refletir sobre como os problemas que envolvem as relações do homem em sociedade vai estruturando de modo que para os que não vivenciam o problema na pele, passam despercebidos, entende como normal.

Respeitar o direito de igualdade que é garantido por Lei Nacional e Internacional Organização das Nações Unidas (ONU). Deve ser cultural, ideológica. Leis atualmente existem para punir os que desrespeitam. E é a pessoa vítima de preconceito, racismo que toma atitude para uma possível reparação, punição.

O problema é a memória histórica que não deixa o fato acontecido diluir, cair no esquecimento? Também, mas discórdias onde há violência que causa dor física, emocional e que não são resolvidas que possibilita entrar em erupção a qualquer momento. Constituindo, assim, em uma ameaça permanente.

Está aí o mundo e o país com várias pendencia, não resolvidas, como a questão de não ter tido uma vontade do poder público, elite dominante de reparar, retratar com a etnia negra, que foram sujeitos na construção do país, do período colonial aos dias atuais. Um entre tantos exemplos da falta de igualdade de direito entre o negro (ou pessoa de cor como era referido na época) e o branco, no decorrer de três séculos de regime escravocrata e 132 anos após a abolição da submissão de trabalho escravo. Russell, (2005) contribui com a discussão não só em questão de equidade, mas de inserção social, ao abordar a criação de companhias:

[...] de cor oficialmente justificada como preparação "contra qualquer contingência". [...] Don Loureço de Almeida durante seu longo mandato como governador - de 1721 a 1732 , deu prosseguimento a esta política, criando companhias onde quer que haja pessoas de cor livres e em quantidade suficiente para formar uma companhia. [...] A lei de 1773 que aboliu a escravidão em Portugal continha uma cláusula pela qual as pessoas de cor por ela libertadas teriam permissão de ocupar todos os cargos e receber todas as honrarias e privilégios. Essa cláusula só aplicável em Portugal e não no império ultramarino, esta cláusula irritou bastante as pessoas de cor livres especialmente os mulatos do Brasil e serviu para fazê-las tomar consciência de sua própria posição desprivilegiada. (RUSSELL, 2005. p.132-139). 
As companhias citadas acima foram criadas em vários lugares do país tais como em Minas Gerais, São Paulo, Bahia entre outros. Eram funções militares que deram abertura para negros e libertos exercerem a função de soldados, pois por falta de pessoas brancas que preenchessem os requisitos, por sobreviver de raízes, caça e terem facilidade de caminhar em trilhas, matas fechadas. Cor era sinônimo de inferioridade, motivos para não participar de questões políticas sociais durante o período colonial. (RUSSELL, 2005).

\section{IGUALDADE DE DIREITO: UM OLHAR SOBRE AS LEIS ABOLICIONISTAS NO BRASIL}

Tantas são as discussões, movimentos reivindicatórios e rebeliões em favor da igualdade de direito entre a população negra e a branca durante e pós o regime escravocrata. A inserção do negro na sociedade brasileira, ainda é um grave problema a ser resolvido. Atualmente, a reivindicação feita por grupos militantes que lutam pela causa, não é mais por igualdade, mas por equidade de direitos, diante da defasagem a ser equiparados. Se antes era uma quantidade de benefícios sociais não usufruídos a partir da abolição da escravidão, que tem 132 anos, nos dias atuais precisa ser reparado.

Muitas são as questões a refletir num processo que durou 338 anos de dominação de uma classe elitizada, proprietária dos meios de produção sobre os trabalhadores despossuídos de direitos, dignidades e da própria vida. Um exemplo da questão posta é a primeira Lei do Ventre Livre de n 2.040 , de 28 de setembro de 1871 .

\footnotetext{
Art. $1^{\circ}$ Os filhos da mulher escrava que nascerem no Império, desde a data desta lei, serão considerados livres.

Parágrafo $1^{\circ}$ Os ditos filhos menores ficarão em poder e sob a autoridade dos senhores de suas mães, os quais terão a obrigação de criá-los até a idade de 8 anos completos.

Parágrafo $2^{\circ}$ Chegando o filho da escrava a esta idade, o senhor da mãe terá a opção ou de receber do Estado a indenização de 600 mil-réis ou de utilizar-se dos serviços do menor até a idade de 21 anos completos. (BRASIL, 1871).
}

A lei do ventre livre não apresentou benefício a etnia africana e nem mesmo favoreceu os descendentes. De acordo com a referida Lei, as crianças ficariam presas, ligadas ao modelo escravista até os vinte e um ano de idade. E nada consta que teriam um meio de se sustentar, contar com programa de inserção social no mercado de trabalho, após sua liberdade.

Outra discrepância que leva a entender que a preocupação era mais simbólica, do que processual no declínio da abolição do regime escravocrata foi a Lei dos 
Sexagenários. Ao conceder liberdade ao negro na condição de escravo, que segundo a Lei de $\mathrm{n}^{\mathrm{o}} 3.270$, de 28 de setembro de 1885, conhecida também por Lei SaraivaCotegipe, "que concedia Liberdade aos escravos com mais de 60 anos de idade" (BRASIL,1885). Conforme a Lei, o liberto tinha por obrigatoriedade indenizar o seu exproprietário, caso não possuísse a quantia, seria paga com serviço de 3 ou até 5 anos, completando 65 anos de idade, entre outras obrigações rígidas. $\mathrm{O}$ cativo dificilmente chegava a essa idade, por não terem qualidade de vida.

A Lei $n^{\circ} 3353$, de 13 de maio de 1888, Lei Áurea ${ }^{3}$, que teoricamente concedeu "liberdade" extinção do trabalho escravo no país foi resultado de pressão dos filhos de fazendeiros, elites, intelectuais (que ao voltar dos estudos no exterior trouxeram as ideias abolicionistas), somando com outros interesses de países, como Inglaterra que tinha se industrializado, os movimentos de resistência dos cativos que com o passar do tempo já estavam conseguindo organizar melhor, unir para os levantes, motins, a formação de quilombolas, tanto nas fazendas como nos centros urbanos, forçou

${ }^{2}$ Conhecida também por Lei Saraiva- Cotegipe, por homenagem a dois senadores José Antônio Saraiva (1823-1893); Barão de Cotegipe (1815-1893). 3



Edição do jornal carioca "Gazeta de Notícias" de 13 de maio de 1888. Disponível em: https://www.todamateria.com.br/lei-aurea. Acesso em:24 de Nov. 2020.

A Lei tinha apenas 2 artigos:

"A Princesa Imperial Regente, em nome de Sua Majestade o Imperador, o Senhor D. Pedro II, faz saber a todos os súditos do Império que a Assembleia Geral decretou e ela sancionou a lei seguinte:

Art. $1^{\circ}$ : É declarada extincta desde a data desta lei a escravidão no Brasil.

Art. $2^{\circ}$ : Revogam-se as disposições em contrário."

BEZERRA, Juliana. Bacharelada e Licenciada em História, pela PUC-RJ. Especialista em Relações Internacionais, pelo Unilasalle-RJ. Mestre em História da América Latina e União Europeia pela Universidade de Alcalá, Espanha. Disponível em: https://www.todamateria.com.br/lei-aurea. Acesso em :24 de Nov. 2020. 
oficializar a libertação dos cativos. Conforme a "Assembleia Geral Decreta: Art. ${ }^{\circ} 1^{\text {o }}$.- É declarada extinta, desde a data dessa lei, a escravidão no Brasil. Art. ${ }^{\circ} 2^{\circ}$.- Revogam si as disposições em contrário" (BRASIL, 1888).

A partir da assinatura da Princesa Isabel, a liberdade dos trabalhadores escravizados tinha respaldo na lei, que contou com apenas os dois artigos citados no parágrafo anterior. Porém, não teve nem uma iniciativa do Estado ou de outro setor da sociedade vigente, que os inserissem na sociedade brasileira como cidadãos e que tivessem direitos de moradia, terras, educação, trabalho entre outros quesitos para terem vida com dignidade e qualidade.

Não foram dados para a maioria dos ex-cativos o direito de serem trabalhadores assalariados. E formou-se assim, uma massa de pessoas livres da condição de cativos, mas despossuídas, ociosas vivendo as margens da sociedade, sem possibilidade de ascensão social.

\section{RAÇA \& RACISMO}

“A memória [...] é uma criação constante do presente, do passado enquanto representação, enquanto imagem impressa na mente" (FUNARI, 2003, p.16). As lembranças da história de vida da linhagem africana remetem a uma identidade de servil, isto é, uma identidade que veio sendo reafirmada por exclusão social, pela mídia. Um exemplo são os papeis representados nas novelas, programas de TV, entre outros, sempre na condição de servir o branco. Embora o objetivo seja retratar a realidade passada, mas para os representados não é uma memória que os fazem bem.

O regime escravocrata no Brasil durou três séculos. Teve início nas primeiras décadas da colonização, sendo um dos últimos a abolir a prática do homem branco contra os indígenas e os africanos. Cento e trinta anos a partir da oficialização jurídica da abolição da escravatura no país.

A assinatura da Princesa Isabel em 1888, não significou justiça aos submetidos a trabalho forçado sem remuneração e respeito a horas de descanso, representa a memória da marginalização. Abolir a escravidão não foi uma opção do governo Imperial, foi o conjunto de forças contrárias vindo de vários setores da sociedade Nacional e Internacional e a incapacidade de conter as ações de resistência dos escravizados. Embora a liberdade, "não acompanhada de igualdade de direito entre a diversidade 
étnica, em particular a negra e a indígena, contribuíram para a construção do Estado Brasileiro". (CUNHA JUNIOR, 2008: p. 7).

Um ano depois da Lei Áurea, o País passou a República ${ }^{4}$. No entanto, não houveram mudanças positivas para os despossuídos e marginalizados. Pelo contrário, com Estado republicano surgiu a ideologia racial seguida de reforço ações não só de branqueamento racial, mas de limpeza dos centros urbanos, forçando a população negra se retirar e ir para os morros, formando as favelas nos grandes centros.

Sobre o racismo centrado na ideologia racial da prioridade a cor de pele branca, como sinônimo de superioridade que enaltece a raça branca perante a raça negra, para Maia e Zamora (2018):

O Brasil é um país que vive o racismo estrutural sustentado na hegemonia da brancura. Isso marca privilégios por parte da população branca e inviabiliza o acesso da população negra, em amplo aspecto, aos territórios existenciais, políticos, econômicos e sociais (MAIA e ZAMORA, 2018. p.283).

As leituras para esta pesquisa fazem perceber que os que representam o Estado político brasileiro republicano, os representantes de direita são racistas. Sobre esta discussão na concepção de Maia e Zamora (2018):

[...] lógica racial está no cerne da busca pela identidade nacional, na fundação do Estado Republicano. Ela "garante" a superioridade da raça branca sobre a negra e a indígena, além de condenar à infertilidade e à inferioridade intelectual os mestiços. (MAIA; ZAMORA, 2018. p.283).

A busca por uma identidade brasileira após assinatura da princesa Isabel que juridicamente reconheceu a "liberdade" dos negros e implantação do regime republicano imperou um status social da raça branca. Um exemplo está na imagem nos livros didáticos onde Jesus Cristo e Tiradentes são de cor branca. As teorias raciais e o ideário de branqueamento da população brasileira fundamentaram na ciência que acreditava em raça superior e inferior e para dar continuidade na ideia de clareamento, $o$ governo financiou a imigração de europeus: italianos, espanhóis, austríacos, alemães com o objetivo de miscigenação.

O resultado de política oligárquica (grupos que dominam o poder e governa de acordo com os seus interesses objetivos) é a busca por igualdade de direito, a formação de grupos militantes, LGBTS, o confronto da população nacional nas relações sociais. Nos dias atuais equidade social, constitui em uma história de lutas, confrontos,

\footnotetext{
${ }^{4}$ Período Colonial 1500 a 1822, Período Imperial 1822 a 1889, republicano de 1889 aos dias atuais.
} 
insatisfação entre a população despossuída, marginalizada e a elite dominante, que detêm o poder e usa o Estado como aparelho ideológico para reprender e manter o domínio sobre a população.

Gilberto Freyre, na obra "Casa Grande e Senzala" foi ingênuo ou defendia os interesses da classe dominante quando argumentou: "mas não se pode acusar de rígida, nem de falta de mobilidade vertical- como diria Sorokin -o regime brasileiro, em vários sentidos sociais um dos mais democráticos, flexíveis e plásticos” (FREYRE, 2001, p.115). A mobilidade vertical descendente? Desceu de cativo a marginalizado, após abolição.

Os movimentos de mobilização e articulação dos militantes da causa, os elementos elencados por Freyre (2001): mobilidade vertical; democracia; flexibilidade e plasticidade constituem uma ofensa, falta de respeito para com os sacrificados, marginalizados e que atualmente clamam por justiça, é uma memória de dor, que reflete na alma a humilhação sofrida.

A miscigenação é fato, mas não foi exitosa, resultou em diversidades de cor, o pardo, amarelo e recebendo denominações não aceitas como: moreninho de cabelo bom, mulata, chocolate, entre outros. A busca por justiça sempre foi uma realidade e a resistência continua.

Se hoje existem leis como a de Cotas, o direito de participar em representação na mídia, em vaga de programas de televisão, papel em novelas, repartições pública privadas e função exercitadas por branco essa iniciativa de inserção social é resultado de manifestações reivindicatórias de afrodescendentes e simpatizantes da causa que lutam por democracia de fato, igualdade de direito de oportunidades, de salários justos de acordo com o trabalho ou função desempenhada e não por cor de pele e ou descendência étnica.

\section{CONSIDERAÇÔES FINAIS}

A história da sociedade brasileira é cheia de contradições, injustiça, desigualdade de direito, oportunidades, poder aquisitivos de bens de consumo básico, alimentos, moradia, saneamento básico, ensino público que forme o cidadão para ter dignidade. É um jogo de poder que alterna na política, na representação social, políticos que comunga, compartilha da mesma ideologia, da exclusão, continuidade do empobrecimento da população. 
Não priorizam planos econômicos, políticos, sociais, para inserção dos sujeitos na sociedade, sem distinção de raça, etnias, grupo social partidário a serem capazes de proverem o próprio sustento com o trabalho desempenhado. Falta igualdade de oportunidade aos ativos que trabalham, estudam e programas de incentivo, saúde mental para os que vivem as margens da sociedade, sejam produtivos, tenham dignidade e sejam capazes de prover o sustento próprio.

Outra ausência está na formação de cidadãos para a inserção social, terem capacidades intelectuais, serem pessoas ativas. Os políticos brasileiros para atender o sistema econômico e político capitalista deveria investir mais em fontes de empregos e garantias para qualificação do trabalhador. Plano emergencial, renda cidadão entre outros programas é paliativo, não soluciona o problema.

Reparar a injustiça cometida com o povo afro e indígena que foram cativos e que os descendentes continuam sendo vítimas do preconceito, racismo é uma necessidade latente que exige que o Estado aja evitando que a sociedade elitizada e privilegiada continue a ver o afrodescendente e o indígena como inferiores incapazes cometendo assim crime de racismo.

A inferiorização do afrodescendente não pode mais ser uma realidade. Os movimentos reacionários têm se organizado promovendo muitos debates, obras relevantes sobre a temática que discutem as raízes do racismo e desigualdade de direito entre as etnias brasileiras.

\section{REFERÊNCIAS}

BRASIL. Lei $\mathbf{n}^{\mathbf{1}} \mathbf{1 2 . 2 8 8}$, de 20 de julho de 2010. Institui o Estatuto da Igualdade Racial; altera as Leis nos 7.716, de 5 de janeiro de 1989, 9.029, de 13 de abril de 1995, 7.347, de 24 de julho de 1985, e 10.778, de 24 de novembro de 2003. Diário Oficial da União, Brasília, 21 jul. 2010.

Lei n. 2.040, de 28 de setembro de 1871. Lei do Ventre Livre ou Lei Rio Branco. Declara de condição livre os filhos de mulher escrava que nasceram desde a data desta lei, libertos os escravos da Nação e outros, e providencia sobre a criação e tratamento daqueles filhos menores e sobre a libertação anual de escravos. Coleção das leis do Império do Brasil. Rio de Janeiro, v. 1, p. 147, 1871.

. Lei n. 3.270, de 28 de setembro de 1885. Regula a extinção gradual do elemento servil. Coleção das leis do Império do Brasil. Rio de Janeiro, v. 1, p. 14, 1886. Disponível em: https://www2.senado.leg.br/bdsf/handle/id/179463. Acesso em: 16, set. 2020. 
Lei n. 581, de 4 de setembro de 1850. Lei Saraiva-Cotegipe ou Lei dos Sexagenários determinou a libertação dos escravos com mais de 60 anos. Coleção das leis do Império do Brasil. Rio de Janeiro, p. 267, v. 1, parte 1, 1850.

Lei no 3.353 de maio de 1888 (Lei Áurea). Declara extinta a escravidão no Brasil. Disponível em: http://www.planalto.gov.brhtm. Acesso em: 24 Nov. 2020.

CARDOSO, C. F. História do Poder, História Política. In: Estudo Ibero Americanos, V, XXIII, n.1, jun. 1997.

COSTA, M. C. Sociologia: Introdução à ciência da Sociedade. São Paulo: Moderna,2005.

FREYRE, Gilberto. Casa-grande \& senzala. 42. ed. Rio de Janeiro: Record, 2001.

FORNER, E. O significado da liberdade. In: Revista Brasileira de História, São Paulo, v. 8 , n. 16 , mar.88/ago.88, p. 9-36.

FUNARI, P. P. A. Antiguidade clássica: a história e a cultura a partir dos documentos. 2. ed. Campinas: Editora da Unicamp, 2003.

MACHADO, C. P. Designação da palavra preconceito nos dicionários. (Mestrado). Programa de Pós-Graduação em Linguística da UNICAMP. São Paulo. 2007.

MAIA, K.S; ZAMORA, M.H.N. O Brasil e a lógica racial: do branqueamento à produção da subjetividade do racismo. In: Psicol. Clin. Rio de Janeiro, v.30, n.2, p.265286, 2018. Disponível em: http://doi.org/10.33208/PC1980. Acesso em:25, set. 2020.

MARINGONI, G. O destino dos negros após a Abolição. IPEA: 2011. Ano 8, 2011. Disponível em: http://www.ipea.gov.brd\%3D28\&Itemid=23. Acesso em: 16, set. 2020.

NASCIMENTO, A. do. O genocídio do negro brasileiro: processo de um racismo mascarado. Rio de Janeiro: Paz e Terra, 1978.

REIS, João. José. Sociedade e Conjuntura Social. In: Rebelião Escrava no Brasil. A história do Levante dos Malês em 1835. São Paulo: Brasiliense, 1986.

RUSSELL-WOOD, A. J. R. Negros e mulatos livres na sociedade da América portuguesa. In: Escravos e libertos no Brasil colonial. Rio de Janeiro: Civilização Brasileira, 2005, p. 105-126.

As aspirações de indivíduos de ascendência africana. In: Escravos e libertos o Brasil colonial. Rio de Janeiro: Civilização Brasileira, 2005, p. 127-142.

VAINFAS, R. Colonização, miscigenação e questão racial: notas sobre equívocos e tabus da historiografia brasileira In: Tempo (UFF). Niterói, v. 8, p. 7-22, 1999.

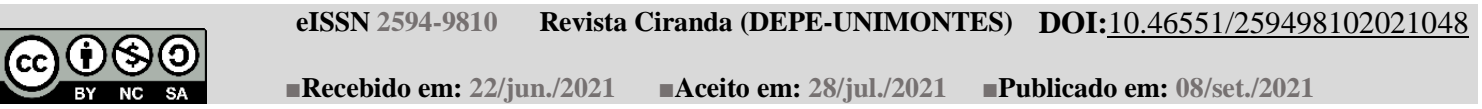

